\title{
The Culture of Incident Reporting and Feedback: A Cross-Sectional Study in a Hospital Setting
}

\author{
Anne Vifladt1,2, Bjoerg 0. Simonsen³, Stian Lydersen4, Per G. Farup ${ }^{1,2}$ \\ ${ }^{1}$ Department of Research, Innlandet Hospital Trust, Brumunddal, Norway \\ ${ }^{2}$ Unit for Applied Clinical Research, Department of Cancer Research and Molecular Medicine, \\ Norwegian University of Science and Technology, Trondheim, Norway \\ ${ }^{3}$ Department of Quality and Patient Safety, Innlandet Hospital Trust, Brumunddal, Norway \\ ${ }^{4}$ Regional Centre for Child and Youth Mental Health and Child Welfare, Norwegian University \\ of Science and Technology, Trondheim, Norway \\ Email: annevi@stud.ntnu.no
}

Received 23 October 2015; accepted 22 November 2015; published 25 November 2015

Copyright (C) 2015 by authors and Scientific Research Publishing Inc.

This work is licensed under the Creative Commons Attribution International License (CC BY).

http://creativecommons.org/licenses/by/4.0/

(c) (i) Open Access

\section{Abstract}

A safety culture where incidents have been reported and feedback given is essential to detect and understand system failures. The aims of this study were to examine the culture of incident reporting and feedback (the incident culture) in a hospital setting, and the associations between the incident culture and other dimensions of the safety culture. A cross-sectional study was carried out with the instrument Hospital Survey on Patient Safety Culture (HSOPSC) within 16 units in six somatic hospitals at a Norwegian Hospital Trust. Units with identical specialities across the hospitals constitute a clinic. HSOPSC measures the health care personnel's perception of the safety culture, seven safety dimensions at the unit level, three at the hospital level and four outcome measures. The outcome measures "Frequency of event reporting" and the dimension "Feedback and communication about error" were combined into the variable "incident culture", score 1 - 5. A positive score was defined as $\geq \mathbf{4 . 0}$. This study included 631 health care personnel. The mean score for the incident culture was 3.10 (SD 0.65) with significant differences between the clinics, and the hospitals. The strongest predictors for the incident culture were the dimensions "Communication openness" (linear regression slope B 0.470; 95\% CI 0.398 to 0.543 ; p < 0.001), "Manager expectations and actions promoting safety" (B 0.378 ; 95\% CI 0.304 to 0.453 ; p < 0.001$)$, "Organisational learning and continuous improvement" (B 0.374; 95\% CI 0.293 to $0.455 ; \mathrm{p}<0.001$ ) and "Teamwork across hospital units" (B $0.360 ; 95 \%$ CI 0.261 to $0.459 ; p<0.001)$. In this study, the incident culture needed improvements. To improve the incident culture, the attention may be directed towards developing and maintaining a culture of open communication, management that promotes safety, and a learning organisation and teamwork between the units. 


\section{Keywords}

\section{HSOPSC, Patient Safety Culture, Patient Safety Incident}

\section{Introduction}

Patient safety incidents (later referred to as incidents) is a well-known challenge in health care, and is by the International Classification for Patient Safety, initiated by the World Health Organisation (2009), defined as an event or circumstance that could have resulted, or did result, in unnecessary harm to a patient ([1], p. 15). Reporting of incidents is one method for identifying errors, detecting system failures and improving the system [2] [3]. Despite this, underreporting of incidents has been suggested [4]. Previously reported barriers towards incident reporting have among others been fear of blame and legal consequences, an uncertainty of which incidents should be reported, consuming time and inadequate feedback [5]. To learn from failures, a culture of safety where the employees feel free to communicate about safety concerns without fear of blame is recommended [6].

The European Society for Quality in Health Care (2006) defines the culture of safety as an integrated pattern of individual and organisational behaviour, based upon shared beliefs and values that continuously seeks to minimise patient harm, which may result from the processes of care delivery ([7], p. 4). In this study, the term "culture" describes the results from a survey of the safety culture. Several instruments have been developed to measure the safety culture in health care organisations [8] [9]. The instrument Hospital Survey on Patient Safety Culture (HSOPSC) [10] has been frequently used to measure the safety culture in hospital settings in Northern Europe [11]-[20]. The assessments of the safety culture can identify areas where improvements are needed [21]. Several other studies have shown a score that can be improved for the safety culture dimensions "Frequency of event reporting" [11] [13] [16] and "Feedback and communication about error" [11]-[13]. The culture dimension "Frequency of event reporting" considers the reporting of mistakes that do not harm the patient [10]. In this study, the two culture dimensions "Frequency of event reporting" and "Feedback and communication about error" were defined as the "incident culture". Previously, in other studies "Feedback and communication about error" and "Feedback about error and communication openness" have been relevant predictors for "Frequency of event reporting" [13] [19]. To improve the incident culture, a broader understanding of which dimensions of the safety culture that is most relevant for the incident culture is of interest to study.

The aims of this study were (i) to examine the incident culture in a hospital setting, and (ii) to investigate the association between the incident culture and other dimensions of the safety culture.

\section{Methods}

\subsection{Study Design}

A cross-sectional survey was carried out in 2008/2009 in units within a Norwegian Hospital Trust. The top management in The Hospital Trust initiated the survey of the safety culture to identify areas for improvements. Anonymous self-reporting surveys were used, where some units replied by an electronic version distributed by email, and other units filled in a paper version of the questionnaire.

\subsection{Hospital Structure}

The Hospital Trust consisted of six somatic hospitals (hospital 1, 2, 3, 4, 5 and 6) spread over a wide geographical area all with medical, surgical and emergency units and one or more other units. Sixteen out of 38 units participated, one to five units per hospital. In this study, units with identical specialities (internal medicine, surgery, etc.) across the hospitals were defined as a clinic (clinic a, b, c, d, e and f).

\subsection{Inclusion and Exclusion Criteria}

Registered nurses, auxiliary nurses and physicians were included in this study. Participants with incompletely filled in questionnaires according to the scoring procedure for the HSOPSC [10], and/or had filled in less than 
two items in one of the dimensions that were used as the measure of the "incident culture" in this study, were excluded.

\subsection{Variables}

\subsubsection{The Safety Culture}

The safety culture was measured with the validated Norwegian version of the instrument HSOPSC [22]. The original HSOPSC was developed by the Agency for Healthcare Research and Quality (AHRQ) [10]. The HSOPSC consists of 42 items, and measures the health care personnel's perception of the dimensions of the safety culture, seven at the unit level, three at hospital level and two multiple items outcome measuring "Frequency of event reporting" and "Overall perceptions of safety". The items were scored on a five-point Likert scale where 1 = strongly disagree/never, 2 = disagree/rarely, $3=$ neither/sometimes, $4=$ agree/most of the time, and $5=$ strongly agree/always [10]. After reversing negatively worded items, the mean score with SD for each dimension was calculated for each participant and all participants. The scores 4 to 5 were defined as satisfactory. For each participant, the proportion of positive response was calculated for each item and each dimension, and the mean proportion of positive response with SD was calculated for all participants. Percent positive response below $50 \%$ was defined as areas where improvements were needed, $51 \%-74 \%$ as moderate and $75 \%$ or higher as satisfactory [10]. In addition, the instrument includes two single items outcome "Patient safety grade" scored as 1 = excellent, 2 = very good, $3=$ acceptable, $4=$ poor and $5=$ failing, and "Number of events reported" scored as $1=$ no event reports, $2=1$ to 2 event reports, $3=3$ to 5 event reports, $4=6$ to 10 event reports, $5=11$ to 20 event reports, and $6=\geq 21$ event reports [10]. Table 1 present the dimensions of the HSOPSC.

When less than half of the items in a dimension were missing, the mean value was calculated from the responded items.

\subsubsection{The Incident Culture}

The dependent variable "incident culture" is the mean score for the six items within the dimensions of the safety culture "Frequency of event reporting" (three items) and "Feedback and communication about error" (three items) measured with HSOPSC [10]. The items consider reporting of mistakes that did not harm the patients, and feedback and communication about errors and implemented changes based on event reports. The items included in the "incident culture" are given in Table 2.

\subsubsection{Participants' Characteristics}

The characteristics of the participants were recorded as follows: gender, age ( $\leq 30,31-40,41-50,51-60, \geq 61$ years), profession (registered nurse, auxiliary nurse, physician), length of service in the unit $(<1,1-5,6-10,11$ $-15,16-20, \geq 21$ years), place of education (inside or outside Scandinavia) and place of work in the hospital trust.

\subsection{Statistics}

First, comparison and association between participant characteristics and the incident culture was analysed using Student t-test, one-way ANOVA and Pearson correlation. Then the association between each of the dimensions of HSOPSC and the incident culture was analysed using Pearson correlation. Further, we used multiple linear regression analyses with incident culture as the dependent variable. These analyses included as independent variables all characteristics of the participants as follows: participant age, place of education and length of service in the unit as covariates, gender, profession and clinic as categorical covariates (fixed factors), hospital as random factor, and the interaction between clinic and hospital. The regression analyses were first carried out including one of the dimensions of the safety culture at a time, and then including the four strongest predictors of the incident culture simultaneously. The outcome measures (HSOPSC) not included in the multiple linear regression were the "Overall perception of safety", "Patient safety grade" and "Number of events reported".

Results are presented as percent positive response, mean (SD), Pearson's correlation coefficient (r) and regressions coefficient B with $95 \%$ confidence interval ( $95 \% \mathrm{CI}$ ). Two-sided $\mathrm{p}<0.05$ were considered statistically significant. SPSS Statistics 18 was used for the analyses.

\subsection{Ethics and Formal Requirements}

The survey was approved by the Privacy Ombudsman for Research, representing The Norwegian Data Inspec- 
Table 1. The dimensions of HSOPSC, scores and associations with the incident culture.

\begin{tabular}{|c|c|c|c|c|c|}
\hline \multirow[b]{2}{*}{ Dimensions of HSOPSC } & \multirow[b]{2}{*}{ n (\%) } & \multirow[b]{2}{*}{$\begin{array}{l}\text { Percent } \\
\text { positive responses } \\
\text { mean (SD) }\end{array}$} & \multirow[b]{2}{*}{$\begin{array}{l}\text { Mean } \\
\text { score (SD) }\end{array}$} & \multicolumn{2}{|c|}{$\begin{array}{l}\text { Correlation with the incident } \\
\text { culture }\end{array}$} \\
\hline & & & & $\mathrm{r}$ & p-value \\
\hline \multicolumn{6}{|l|}{ Unit Level } \\
\hline Manager expectations and actions promoting safety & 631 & $73(30)$ & $3.87(0.64)$ & 0.413 & $<0.001$ \\
\hline Organisational learning and continuous improvement & 628 & $53(34)$ & $3.50(0.60)$ & 0.418 & $<0.001$ \\
\hline Teamwork within hospital units & 631 & $79(28)$ & $4.04(0.54)$ & 0.280 & $<0.001$ \\
\hline Communication openness & 631 & $71(33)$ & $3.85(0.62)$ & 0.503 & $<0.001$ \\
\hline Feedback and communication about error & 631 & $48(35)$ & $3.39(0.75)$ & - & - \\
\hline Non-punitive response to error & 631 & $80(29)$ & $4.00(0.61)$ & 0.239 & $<0.001$ \\
\hline Staffing & 631 & $56(29)$ & $3.55(0.59)$ & 0.153 & $<0.001$ \\
\hline \multicolumn{6}{|l|}{ Hospital Level } \\
\hline Hospital management support for patient safety & 616 & $32(35)$ & $3.05(0.74)$ & 0.351 & $<0.001$ \\
\hline Teamwork across hospital units & 627 & $44(33)$ & $3.35(0.53)$ & 0.336 & $<0.001$ \\
\hline Hospital handoffs and transitions & 622 & $54(33)$ & $3.51(0.55)$ & 0.206 & $<0.001$ \\
\hline \multicolumn{6}{|l|}{ Outcome } \\
\hline Overall perceptions of safety & 630 & $64(32)$ & $3.67(0.62)$ & 0.312 & $<0.001$ \\
\hline Frequency of event reporting & 631 & $22(33)$ & $2.81(0.78)$ & - & - \\
\hline Patient safety grade (Single item) & 623 & & & & \\
\hline Excellent & $15(2.4)$ & & & & \\
\hline Very good & $404(64.8)$ & & & & \\
\hline Acceptable & $192(30.8)$ & & & & \\
\hline Poor & $12(1.9)$ & & & & \\
\hline Failing & 0 & & & -0.347 & $<0.001$ \\
\hline Number of events reported (Single item) & 625 & & & & \\
\hline No reports & $260(41.6)$ & & & & \\
\hline 1 - 2 reports & $237(37.9)$ & & & & \\
\hline 3 - 5 reports & $88(14.1)$ & & & & \\
\hline 6 - 10 reports & $24(3.8)$ & & & & \\
\hline 11 - 20 reports & $12(1.9)$ & & & & \\
\hline$\geq 21$ reports & $4(0.6)$ & & & 0.123 & 0.002 \\
\hline
\end{tabular}

torate. The participation was voluntary, and the survey was performed anonymously. The participants received written information about the survey and the use of data for research.

\section{Results}

\subsection{Participants' Characteristics and the Safety Culture}

Out of 1172 invited health care personnel, 631 were included in the analysis (response rate 54\%). Figure 1 shows a flow chart of the participants. The median age was the group 41 to 50 years, 493 (81.2\%) were female, and median length of service in the unit was the group six to ten years. Table 3 gives the participants' characteristics. 
Table 2. Percent positive response and the mean score with SD for each item included in the variable incident culture.

Items

Frequency of event reporting:

When a mistake is made, but is caught and corrected before affecting the patient, how often is this reported?

When a mistake is made, but has no potential to harm the patient, how often is this reported?

When a mistake is made that could harm the patient, but does not, how often is this reported?

\section{Feedback and communication about error:}

We are given feedback about changes put into place based on event reports.

We are informed about errors that happen in this unit.

In this unit, we discuss ways to prevent errors from happening again.

Sum (incident culture)

The dimensions and items presented in the table are part of the HSOPSC questionnaire.

Table 3. Characteristics of participants and their association with the incident culture.

\begin{tabular}{|c|c|c|c|c|}
\hline Characteristics Total = 631 & Groups & n (\%) & The incident culture Mean (SD) & p-value \\
\hline \multirow{2}{*}{ Gender $(n=607)$} & Female & $493(81.2)$ & $3.09(0.65)$ & \\
\hline & Male & $114(18.8)$ & $3.09(0.59)$ & $0.998^{\mathrm{A}}$ \\
\hline \multirow{5}{*}{ Age $(n=617)$} & $\leq 30$ years & $65(10.5)$ & $2.99(0.62)$ & \\
\hline & 31 - 40 years & 145 (23.5) & $2.96(0.53)$ & \\
\hline & 41 - 50 years & 197 (31.9) & $3.06(0.66)$ & \\
\hline & 51 - 60 years & $180(29.2)$ & $3.24(0.69)$ & \\
\hline & $\geq 61$ years & $30(4.9)$ & $3.25(0.71)$ & $<0.001^{\mathrm{B}}$ \\
\hline \multirow{3}{*}{ Profession $(n=631)$} & Registered nurse & $495(78.4)$ & $3.08(0.66)$ & \\
\hline & Auxiliary nurse & $48(7.6)$ & $3.21(0.62)$ & \\
\hline & Physician & 88 (13.9) & $3.15(0.56)$ & $0.273^{\mathrm{C}}$ \\
\hline \multirow{6}{*}{ Length of service in the unit $(n=625)$} & $<1$ years & $52(8.3)$ & $2.99(0.62)$ & \\
\hline & 1 - 5 years & $160(25.6)$ & $3.04(0.62)$ & \\
\hline & 6 - 10 years & $157(25.1)$ & $3.08(0.68)$ & \\
\hline & 11 - 15 years & $100(16.0)$ & $3.10(0.67)$ & \\
\hline & 16 - 20 years & 68 (10.9) & $3.12(0.59)$ & \\
\hline & $\geq 21$ years & $88(14.1)$ & $3.26(0.66)$ & $0.005^{\mathrm{B}}$ \\
\hline \multirow{2}{*}{ Place of education $(n=604)$} & Inside Scandinavia & $575(95.2)$ & $3.08(0.64)$ & \\
\hline & Outside Scandinavia & $29(4.8)$ & $3.25(0.64)$ & $0.166^{\mathrm{A}}$ \\
\hline \multirow{6}{*}{ Clinic $(n=631)$} & $\mathrm{a}$ & $92(14.6)$ & $3.12(0.61)$ & \\
\hline & $\mathrm{b}$ & $194(30.7)$ & $2.98(0.61)$ & \\
\hline & C & $267(42.3)$ & $3.13(0.68)$ & \\
\hline & $\mathrm{d}$ & $50(7.9)$ & 3.14 (0.59) & \\
\hline & $\mathrm{e}$ & $21(3.3)$ & $3.60(0.57)$ & \\
\hline & $\mathrm{f}$ & $7(1.1)$ & $2.73(0.26)$ & $<0.001^{\mathrm{C}}$ \\
\hline \multirow{6}{*}{ Hospital $(n=631)$} & 1 & $144(22.8)$ & $2.92(0.63)$ & \\
\hline & 2 & $269(42.6)$ & $3.13(0.59)$ & \\
\hline & 3 & $55(8.7)$ & $3.20(0.58)$ & \\
\hline & 4 & $35(5.5)$ & $3.12(0.88)$ & \\
\hline & 5 & $22(3.5)$ & $2.89(0.68)$ & \\
\hline & 6 & $106(16.8)$ & $3.24(0.68)$ & $0.001^{\mathrm{C}}$ \\
\hline
\end{tabular}

Student t-test ${ }^{\mathrm{A}}$, Pearson correlation ${ }^{\mathrm{B}}$ and one-way ANOVA ${ }^{\mathrm{C}}$. Clinic a, b, c, d, e and $\mathrm{f}$ express units with identical specialities across the hospital. Hospital 1, 2, 3, 4, 5 and 6 express the six somatic hospitals within the Hospital Trust. 


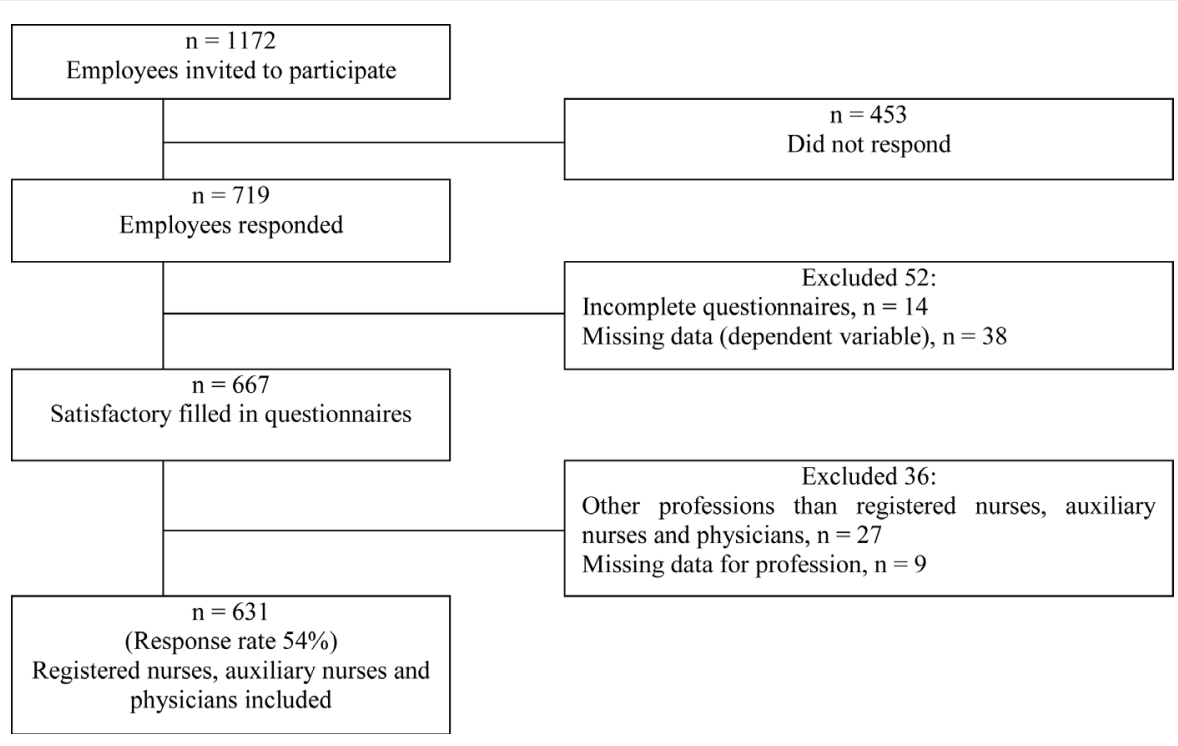

Figure 1. Participation in the study.

The mean proportion positive responses for the safety dimensions of the HSOPSC varied from 22\% (SD 33\%) to $80 \%$ (SD 29\%), and the mean scores from 2.81 (SD 0.78) to 4.04 (SD 0.54). Table 1 gives the scores of all dimensions of the safety culture.

\subsection{The Incident Culture}

The mean proportion positive response for the incident culture was 35\% (SD 28\%), and the mean score was 3.10 (SD 0.65). All of the items included in the dependent variable "incident culture" needed improvements, apart from one item that received a moderate score. The score for the two dimensions within the dependent variable are presented in Table 1, and for each item within the dependent variable in Table 2. Comparisons and correlations between the incident culture and the characteristics of the participants are presented in Table 3.

\subsection{Predictors for the Incident Culture}

In the multiple linear regression analyses, "Communication openness" was the strongest predictor for incident culture, followed by "Manager expectations and actions promoting safety", "Organisational learning and continuous improvement", and "Teamwork across hospital units". The interaction between clinics and hospitals was statistically significantly ( $<0.001$ to 0.001 ) associated with the incident culture (data not shown). Table 4 gives the results of the multiple linear regression analyses when the interaction between clinics and hospitals was included. Figure 2 shows the interaction by presenting the estimated marginal means of the incident culture at each unit after adjustment for the characteristics of the participants. The differences in the incident culture were larger between the units than between the clinics and hospitals.

Finally the four strongest predictors of the incident culture: "Communication openness", "Manager expectations and actions promoting safety", "Organisational learning and continuous improvement" and "Teamwork across hospital units" (according to unstandardized coefficients in multiple linear regression analyses) were included in a multiple linear regression analysis adjusted for the characteristics of the participants. The interaction between clinic and hospital, and all of the safety dimensions included were statistically significantly associated with the incident culture, while gender, age, profession, length of service in the unit, place of education, clinic and hospital were not. "Communication openness" showed the strongest association. The results are presented in Table 4.

\section{Discussion}

In this study, the two safety dimensions included in the incident culture were detected as areas where improvements were needed, in accordance with other surveys of the safety culture in Norwegian hospital settings [11] 


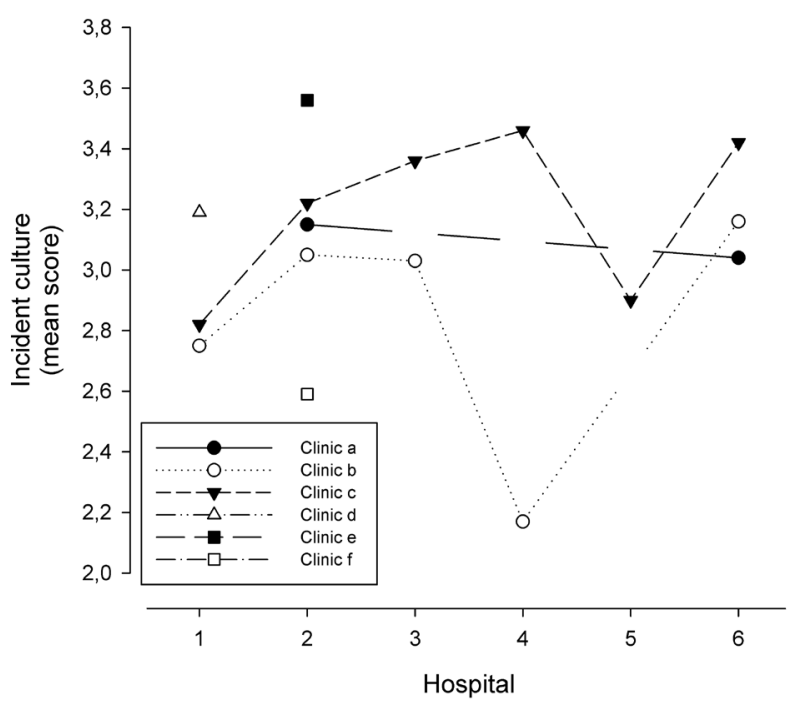

Figure 2. The incident culture in the units, clinics and hospitals. Each point shows the incident culture (given as estimated marginal means) in one unit after adjustment for the characteristic of the participants.

Table 4. Linear regression analyses with incident culture as the dependent variable. All analyses were adjusted for the characteristics of the participants (gender, age, profession, length of service in the unit, place of education, clinic, hospital and the interaction between clinic and hospital) as covariates.

\begin{tabular}{|c|c|c|c|c|c|c|c|}
\hline \multirow{2}{*}{$\begin{array}{l}\text { Dimensions of the } \\
\text { safety culture }\end{array}$} & \multicolumn{4}{|c|}{$\begin{array}{l}\text { The safety culture dimensions as covariate } \\
\text { (Included one at a time) }\end{array}$} & \multicolumn{3}{|c|}{$\begin{array}{l}\text { The four strongest predictors of the incident } \\
\text { culture as covariates (Included simultaneously) } \\
(\mathrm{n}=583)\end{array}$} \\
\hline & $\mathrm{n}$ & $\begin{array}{l}\text { Regressions } \\
\text { coefficient B }\end{array}$ & $95 \% \mathrm{CI}$ & p-value & $\begin{array}{l}\text { Regressions } \\
\text { coefficient B }\end{array}$ & $95 \%$ CI & p-value \\
\hline Communication openness & 589 & 0.470 & 0.398 to 0.543 & $<0.001$ & 0.330 & 0.248 to 0.412 & $<0.001$ \\
\hline $\begin{array}{l}\text { Manager expectations } \\
\text { and actions promoting safety }\end{array}$ & 589 & 0.378 & 0.304 to 0.453 & $<0.001$ & 0.109 & 0.024 to 0.194 & 0.012 \\
\hline $\begin{array}{l}\text { Organisational learning and } \\
\text { continuous improvement }\end{array}$ & 586 & 0.374 & 0.293 to 0.455 & $<0.001$ & 0.164 & 0.081 to 0.248 & $<0.001$ \\
\hline $\begin{array}{l}\text { Teamwork across } \\
\text { hospital units }\end{array}$ & 586 & 0.360 & 0.261 to 0.459 & $<0.001$ & 0.150 & 0.055 to 0.245 & 0.002 \\
\hline $\begin{array}{l}\text { Teamwork within } \\
\text { hospital units }\end{array}$ & 589 & 0.288 & 0.196 to 0.380 & $<0.001$ & & & \\
\hline $\begin{array}{l}\text { Hospital management } \\
\text { support for patient safety }\end{array}$ & 577 & 0.249 & 0.174 to 0.324 & $<0.001$ & & & \\
\hline Non-punitive response to error & 589 & 0.219 & 0.137 to 0.301 & $<0.001$ & & & \\
\hline $\begin{array}{l}\text { Hospital handoffs } \\
\text { and transitions }\end{array}$ & 581 & 0.173 & 0.078 to 0.268 & $<0.001$ & & & \\
\hline Staffing & 589 & 0.142 & 0.051 to 0.232 & 0.002 & & & \\
\hline
\end{tabular}

[12]. All of the dimensions of the safety culture within unit level and hospital level included in the multiple linear regressions analyses were shown to be predictors for the incident culture, in particular, "Communication openness", "Manager expectations and actions promoting safety", "Organisational learning and continuous improvement" and "Teamwork across hospital units".

\subsection{The Incident Culture}

The low score for the incident culture was explained by the low score for the items included in the culture dimension "Frequency of event reporting". In particular, the item that considers reporting of mistakes with "no 
potential harm to the patient" received a score that was to be improved. The result means that reporting of near-misses can be improved, as shown in other studies carried out in Norwegian hospitals [11] [12]. The hospital trust implemented an electronic reporting system three years before this study was carried out. For this reason, established procedures regarding which incidents to be reported might not yet be fully implemented.

The interaction between clinics and hospitals revealed an incident culture in the unit that was independent of the hospital and the clinic, and with variation between the units. The variation suggests different incident culture across the units within this hospital trust. This result supports the belief that safety improvements should be carried out at unit level [23].

\subsection{Predictors for the Incident Culture}

In this study, the dimension "Communication openness" was shown to be the strongest predictor for a positive incident culture. The result suggests that safety cultures where healthcare personnel freely can share safety concerns with colleagues are of importance for a positive incident culture. Feedback about error and communication openness has previously shown to be a predictor for frequency of event reporting in a survey of the safety culture in a Swiss University Hospital [19]. In a survey among pharmacists in the US, communication openness was conductive to reporting medical error, they found no such significant association between feedback and communication about error and reporting medical errors [24]. However, other studies have shown that lack of feedback is perceived as a barrier for incident reporting among physicians and nurses [25] [26]. The overall score for communication openness was almost satisfactory but lower than shown in a Swedish survey of the safety culture in the hospital settings [14]. The positive result for this dimension can be explained by the health care personnel's length of service in the unit (median six to ten years). A stable group with collaboration for years may facilitate the sharing of experiences and knowledge about safety concerns with colleagues.

The dimension "Manager expectations and actions promoting safety" was the second strongest predictor for a satisfactory incident culture. A management that promotes actions to improve a culture of safety may facilitate an improved incident culture. Such actions can be facilitation of procedures for incident reporting, allocation of time and channels for feedback from incident reports. In accordance with other studies, the health care personnel reported an almost satisfactory score for management support for safety [12] [14] [17]. As described by Westrum (2004), it is important that leaders emphasize behaviour where the right information is given to the right person in the right form and in the right time frame ([27], p. 23).

"Organisational learning and continuous improvement" was shown to be the third strongest predictor for a satisfactory incident culture. The result suggests that a learning organisation with attention towards activities to improve the safety, and where mistakes lead to improvements are more likely to have a positive incident culture. As shown in other surveys, this dimension was scored moderately [12] [14]-[16]. However, a survey in Belgian hospitals, an acute hospital reported a satisfactory score for learning organisation [17].

"Teamwork across hospital units" was the safety dimension at the hospital level that was shown to be the strongest predictor for the incident culture. The result means that cooperation between units to provide satisfactory care for the patients may contribute to a positive incident culture. Teamwork across hospital units received a score where improvements are recommended, as shown in previous studies [11] [12] [15] [16]. Knowing that errors occur when transferring patients between units [28], a satisfactory teamwork across hospital units should be given priority.

A "Non-punitive response to error" has shown a positive association with the dimension "Number of events reported" in a previous study [29], and has been highlighted as essential for incident reporting [30]. The dimension non-punitive response to error was in this study detected as a predictor for the incident culture, but not as the strongest one. However, this dimension received one of the most satisfactory scores for all of the dimensions. "Hospital management support for patient safety" received a score that was to be improved, and was less associated with the incident culture, probably because the top management's support for patient safety may be less visible for health care personnel at the units. As previously discussed by Turunen (2013), reducing the gap between the healthcare personnel and the hospital management regarding patient safety is of importance [20].

To improve the organisational learning from failure, Edmondson (2004) describe a leadership that initiate visions that motivates to positive changes, development of an environment where people openly can communicate and report safety concerns without fear of blame, and engagement of teams in learning processes [6]. 


\subsection{Strengths and Limitations}

The questionnaire HSOPSC has been used internationally and is validated in several languages, including Norwegian. Although, surveys are commonly used and accepted as a method for evaluation of the safety culture, other methods, e.g. anthropological methods could have resulted in different conclusions.

The variable "incident culture", which was a combination of the dimensions "Frequency of event reporting" and "Feedback and communication about error", was made for use in this study. This variable has not been formally validated, but a formal validation of the questionnaire with all the dimensions has been thoroughly validated before [22].

In all, the selection of the participants was judged as representative of the health care personnel in the hospital trust, but not necessarily so within all units, e.g. in units with a low response rate.

The high proportion of females in the study was representative of the health care personnel in the hospital trust, where most auxiliary nurses and registered nurses were female. The relative proportions of auxiliary nurses, physicians and registered nurses were also in large as seen in the hospital trust.

Only 16 out of 38 units in the hospital trust participated. In the participating units, the overall response rate was $54 \%$, less than $65 \%$ that are recommended as a minimum to reduce the risk of bias [31]. The response rate varied significantly between the units.

\section{Conclusion}

In this study, the score for the incident culture was to be improved. For improvements, we found that a positive incident culture was associated with an open communication where health care personnel were confident with sharing experiences from incidents, a management that emphasized patient safety, a learning organisation where experiences and knowledge from incidents were utilized to improve practice and cooperation between hospital units to provide the best quality of care.

\section{Acknowledgements}

The authors wish to thank Jon Petter Blixt, Innlandet Hospital Trust and Randi Ballangrud, Gjoevik University College for conducting the data collection and valuable discussions, and Innlandet Hospital Trust for permission to use the data for research.

\section{Authors' Contributions}

AV has prepared the data file, performed the statistical analyses, interpreted the results and written the manuscript. BOS has contributed to acquisition of data and has given valuable input through the whole process from data collection to completion of the paper. SL is responsible for the statistical analyses. PGF is the guarantor, project leader and main supervisor and has been responsible for the integrity of the work as a whole from inception to published article. All authors have read and approved the final manuscript.

\section{Funding}

This work was supported by funding from Innlandet Hospital Trust and South-Eastern Norway Regional Health Authority, Norway.

\section{Competing Interests}

The authors declare that they have no competing interests.

\section{References}

[1] WHO (2009) More than Words. Conceptual Framework for the International Classification for Patient Safety. Version 1.1. Final Technical Report 2009. World Health Organization, World Alliance for Patient Safety. http://www.who.int/patientsafety/taxonomy/icps full report.pdf

[2] WHO (2005) WHO Draft Guidelines for Adverse Event Reporting and Learning Systems: From Information to Action. World Health Organization, World Alliance for Patient Safety.

[3] Kohn, L.T., Corrigan, J.M. and Donaldson, M.S. (2000) Executive Summary. In: Kohn, L.T., Corrigan, J.M., 
Donaldson, M.S., Eds., To Err Is Human: Building a Safer Health System, Institute of Medicine, National Academy Press, Washington DC, 1-16.

[4] Sari, A.B., Sheldon, T.A., Cracknell, A. and Turnbull, A. (2007) Sensitivity of Routine System for Reporting Patient Safety Incidents in an NHS Hospital: Retrospective Patient Case Note Review. BMJ, 334, 79. http://dx.doi.org/10.1136/bmj.39031.507153.AE

[5] Pfeiffer, Y., Manser, T. and Wehner, T. (2010) Conceptualising Barriers to Incident Reporting: A Psychological Framework. Quality \& Safety in Health Care, 19, e60. http://dx.doi.org/10.1136/qshc.2008.030445

[6] Edmondson, A.C. (2004) Learning from Failure in Health Care: Frequent Opportunities, Pervasive Barriers. Quality \& Safety in Health Care, 13, ii3-ii9. http://dx.doi.org/10.1136/qshc.2003.009597

[7] EUNetPaS (2010) Use of Patient Safety Culture Instruments and Recommendations. http://www.pasq.eu/DesktopModules/BlinkQuestionnaires/QFiles/448_WP4_REPORT\%20\%20Use\%20of\%20\%20PS CI\%20and\%20recommandations\%20-\%20March\%20\%202010.pdf

[8] Colla, J.B., Bracken, A.C., Kinney, L.M. and Weeks, W.B. (2005) Measuring Patient Safety Climate: A Review of Surveys. Quality \& Safety in Health Care, 14, 364-366. http://dx.doi.org/10.1136/qshc.2005.014217

[9] Flin, R., Burns, C., Mearns, K., Yule, S. and Robertson, E.M. (2006) Measuring Safety Climate in Health Care. Quality \& Safety in Health Care, 15, 109-115. http://dx.doi.org/10.1136/qshc.2005.014761

[10] Sorra, J.S. and Nieva, V.F. (2004) Hospital Survey on Patient Safety Culture (Prepared by Westat, under Contract No.290-96-0004).

http://www.ahrq.gov/sites/default/files/wysiwyg/professionals/quality-patient-safety/patientsafetyculture/hospital/resou rces/hospcult.pdf

[11] Haugen, A.S., Softeland, E., Eide, G.E., Nortvedt, M.W., Aase, K. and Harthug, S. (2010) Patient Safety in Surgical Environments: Cross-Countries Comparison of Psychometric Properties and Results of the Norwegian Version of the Hospital Survey on Patient Safety. BMC Health Services Research, 10, 279. http://dx.doi.org/10.1186/1472-6963-10-279

[12] Olsen, E. (2007) Workers' Perception of Safety Culture at a Hospital. Tidsskrift for den Norske Lageforening, 127, 2656-2660.

[13] Ballangrud, R., Hedelin, B. and Hall-Lord, M.L. (2012) Nurses’ Perceptions of Patient Safety Climate in Intensive Care Units: A Cross-Sectional Study. Intensive and Critical Care Nursing, 28, 344-354. http://dx.doi.org/10.1016/j.iccn.2012.01.001

[14] Nordin, A., Wilde-Larsson, B., Nordstrom, G. and Theander, K. (2013) Swedish Hospital Survey on Patient Safety Culture-Psychometric Properties and Health Care Staff's Perception. Open Journal of Nursing, 3, 41-50. http://dx.doi.org/10.4236/ojn.2013.38A006

[15] Hellings, J., Schrooten, W., Klazinga, N. and Vleugels, A. (2007) Challenging Patient Safety Culture: Survey Results. International Journal of Health Care Quality Assurance, 20, 620-632. http://dx.doi.org/10.1108/09526860710822752

[16] Wagner, C., Smits, M., Sorra, J. and Huang, C.C. (2013) Assessing Patient Safety Culture in Hospitals across Countries. International Journal for Quality in Health Care, 25, 213-221. http://dx.doi.org/10.1093/intqhc/mzt024

[17] Vlayen, A., Hellings, J., Claes, N., Peleman, H. and Schrooten, W. (2012) A Nationwide Hospital Survey on Patient Safety Culture in Belgian Hospitals: Setting Priorities at the Launch of a 5-Year Patient Safety Plan. BMJ Quality and Safety, 21, 760-767. http://dx.doi.org/10.1136/bmjqs-2011-051607

[18] Smits, M., Wagner, C., Spreeuwenberg, P., van der Wal, G. and Groenewegen, P.P. (2009) Measuring Patient Safety Culture: An Assessment of the Clustering of Responses at Unit Level and Hospital Level. Quality \& Safety in Health Care, 18, 292-296. http://dx.doi.org/10.1136/qshc.2007.025965

[19] Pfeiffer, Y. and Manser, T. (2010) Development of the German Version of the Hospital Survey on Patient Safety Culture: Dimensionality and Psychometric Properties. Safety Science, 48, 1452-1462. http://dx.doi.org/10.1016/j.ssci.2010.07.002

[20] Turunen, H., Partanen, P., Kvist, T., Miettinen, M. and Vehvilainen-Julkunen, K. (2013) Patient Safety Culture in Acute Care: A Web-Based Survey of Nurse Managers' and Registered Nurses' Views in Four Finnish Hospitals. International Journal of Nursing Practice, 19, 609-617. http://dx.doi.org/10.1111/ijn.12112

[21] Nieva, V.F. and Sorra, J. (2003) Safety Culture Assessment: A Tool for Improving Patient Safety in Healthcare Organizations. Quality \& Safety in Health Care, 12, ii17-ii23. http://dx.doi.org/10.1136/qhc.12.suppl_2.ii17

[22] Olsen, E. (2008) Reliability and Validity of the Hospital Survey on Patient Safety Culture at a Norwegian Hospital. In: Oevretveit, J. and Sousa, P.J., Eds., Quality and Safety Improvement Research: Methods and Research Practice from the International Quality Improvement Research Network, National School of Public Health, Lisbon, 173-186.

[23] Pronovost, P.J., Goeschel, C.A., Marsteller, J.A., Sexton, J.B., Pham, J.C. and Berenholtz, S.M. (2009) Framework for 
Patient Safety Research and Improvement. Circulation, 119, 330-337. http://dx.doi.org/10.1161/CIRCULATIONAHA.107.729848

[24] Patterson, M.E., Pace, H.A. and Fincham, J.E. (2013) Associations between Communication Climate and the Frequency of Medical Error Reporting among Pharmacists within an Inpatient Setting. Journal of Patient Safety, 9, 129133. http://dx.doi.org/10.1097/PTS.0b013e318281edcb

[25] Rashed, A. and Hamdan, M. (2015) Physicians' and Nurses’ Perceptions of and Attitudes toward Incident Reporting in Palestinian Hospitals. Journal of Patient Safety. http://dx.doi.org/10.1097/PTS.0000000000000218

[26] Evans, S., Berry, J., Smith, B., Esterman, A., Selim, P., O’Shaughnessy, J., et al. (2006) Attitudes and Barriers to Incident Reporting: A Collaborative Hospital Study. Quality \& Safety in Health Care, 15, 39-43. http://dx.doi.org/10.1136/qshc.2004.012559

[27] Westrum, R. (2004) A Typology of Organisational Cultures. Quality \& Safety in Health Care, 13, ii22-ii27. http://dx.doi.org/10.1136/qshc.2003.009522

[28] Saastad, E. and Flesland, O. (2015) Årsrapport 2014 for meldeordningen for uønskede hendelser i spesialisthelsetjenesten [Annual Report 2014. Adverse Events Reported from the Specialist Health Services to the Patient Safety Reporting and Learning Systems Unit]. The Norwegian Knowledge Center for the Health Services, Oslo.

http://www.kunnskapssenteret.no/publikasjoner/arsrapport-2014-for-meldeordningen-for-uonskede-hendelser-i-spesiali sthelsetjenesten

[29] Snijders, C., Kollen, B.J., van Lingen, R.A., Fetter, W.P. and Molendijk, H. (2009) Which Aspects of Safety Culture Predict Incident Reporting Behavior in Neonatal Intensive Care Units? A Multilevel Analysis. Critical Care Medicine, 37, 61-67. http://dx.doi.org/10.1097/CCM.0b013e31819300e4

[30] Leape, L.L. (2002) Reporting of Adverse Events. The New England Journal of Medicine, 347, 1633-1638. http://dx.doi.org/10.1056/NEJMNEJMhpr011493

[31] Polit, D. and Beck, C. (2012) Data Collection in Quantitative Research. In: Polit, D. and Beck, C., Eds. Nursing Research, Generating and Assessing Evidence for Nursing Practice, 9th Edition, Wolters Kluwer Health/Lippincott Williams \& Wilkins, Philadelphia, 293-327.

\section{Abbreviations}

(HSOPSC): Hospital Survey on Patient Safety Culture. 